\title{
Ventilation Efficiency and Respiratory Muscle Function at Different Levels of CPAP in Intubated Prematurely Born Infants
}

\author{
Theodore Dassios, Paul Dixon, and Anne Greenough
}

\begin{abstract}
BACKGROUND: CPAP improves respiratory function in prematurely born infants by establishing and maintaining functional residual capacity, but the level of CPAP that optimizes respiratory function has not been adequately described. We compared ventilation efficiency and respiratory muscle function at different levels of CPAP. METHODS: We studied spontaneously breathing, intubated convalescent premature infants at King's College Hospital NHS Foundation Trust and calculated the ventilation efficiency index and the respiratory muscle time constant of relaxation $(\tau)$ at the end of 3 consecutive 5-min periods at 4,6 , and $8 \mathrm{~cm} \mathrm{H} \mathrm{H}_{2} \mathrm{O}$ of CPAP delivered in random order. RESULTS: Between February 2016 and August 2016, 38 infants with a median gestational age of 27 (interquartile range [IQR], 25-30) weeks and a median birthweight of 0.88 (IQR, 0.73-1.02) $\mathrm{kg}$ were studied. At a CPAP level of $6 \mathrm{~cm} \mathrm{H}_{2} \mathrm{O}$, the median ventilation efficiency index was higher (1.52 [IQR, 1.02-2.27]) and median $\tau$ was lower (15.6 [IQR, 10.1-21.3]) s/cm $\left.\mathrm{H}_{2} \mathrm{O}\right]$ compared with the median ventilation efficiency index $(0.75$ [IQR, 0.56-1.03]) and median $\tau(23.3$ [IQR, 15.4-35.2] sec/cm $\left.\mathrm{H}_{2} \mathrm{O}\right)$ at CPAP of $4 \mathrm{~cm} \mathrm{H}_{2} \mathrm{O}(P<.001$ for both $)$. At a CPAP level of $8 \mathrm{~cm} \mathrm{H}_{2} \mathrm{O}$, median ventilation efficiency index was significantly lower $(1.27$ [IQR, 1.04-1.91]) and median $\tau$ was not significantly different $\left(11.2\right.$ [IQR, 8.3-18.9] $\left.\mathrm{s} / \mathrm{cm} \mathrm{H}_{2} \mathrm{O}\right)$ compared with ventilation efficiency index and $\tau$ at CPAP of $6 \mathrm{~cm} \mathrm{H}_{2} \mathrm{O}(P<.001$ and $P=.12$, respectively). After multiple logistic regression, the level of CPAP was independently associated with the ventilation efficiency index (adjusted $P<.001$ ) and $\tau$ (adjusted $P=.003$ ). CONCLUSIONS: Increasing the level of CPAP from 4 to $6 \mathrm{~cm} \mathrm{H}_{2} \mathrm{O}$ was associated with enhanced ventilation efficiency and respiratory muscle function in convalescent premature infants on ventilation, but there was no further benefit from increasing the pressure $>\mathbf{6} \mathbf{~ c m ~} \mathbf{H}_{2} \mathbf{O}$. Key words: continuous positive airway pressure; ventilation efficiency; respiratory muscle function; respiratory muscle rate of relaxation; newborn infants; premature. [Respir Care 2019;64(3):285-291. ㅇ 2019 Daedalus Enterprises]
\end{abstract}

\section{Introduction}

CPAP is widely used in neonatal intensive care as a form of noninvasive respiratory support. ${ }^{1} \mathrm{CPAP}$ improves respiratory function in prematurely born infants by increasing the functional residual capacity and splinting

\footnotetext{
Dr Dassios is affiliated with Neonatal Intensive Care Centre, King's College Hospital NHS Foundation Trust, London, United Kingdom. Dr Dassios and Dr Greenough are affiliated with Women and Children's Health, School of Life Course Sciences, Faculty of Life Sciences and Medicine, King's College London, London, United Kingdom. Prof Dixon is an individual consultant, London, United Kingdom; Mr Greenough is affiliated with National Institute for Health Research Biomedical Centre at Guy's and St Thomas NHS Foundation Trust and King's College London, London, United Kingdom.
}

open the upper airway. ${ }^{2}$ Although numerous studies have qualitatively described the beneficial effect of CPAP on respiratory function,,$^{2,3}$ few studies have investigated the optimal value of the distending pressure. Theoretically, a very low distending pressure would allow for atelectasis, which negatively impacts on oxygenation and increases the work of breathing by imposing the added work of

\footnotetext{
The research was supported by the National Institute for Health Research (NIHR) Biomedical Research Centre based at Guy's and St Thomas' NHS Foundation Trust and King's College London. The views expressed are those of the author(s) and not necessarily those of the NHS, the NIHR, or the Department of Health.

The study was performed at Neonatal Intensive Care Centre, King's College Hospital NHS Foundation Trust, London, United Kingdom.
} 
opening atelectatic areas breath by breath. ${ }^{2}$ Yet, a veryhigh distending pressure would increase the risk of pneumothorax $^{1}$ and cause hyperinflation and place the diaphragm at a mechanical disadvantage. ${ }^{4}$ The efficiency of ventilation would also be affected at a very high distending pressure because ventilation at the upper part of the compliance curve becomes less efficient. ${ }^{5}$

Few studies have investigated the effect of increasing levels of CPAP on respiratory function. Those studies were conducted in populations that consisted of 10 to 20 infants who received noninvasive CPAP by using electrical impedance tomography, ${ }^{6}$ respiratory, ${ }^{7}$ or electromagnetic inductive ${ }^{8}$ plethysmography. Results of these studies concluded that increasing levels of CPAP increased the endexpiratory lung volume and decreased the work of breathing. To our knowledge, there is no published evidence on the effect of varying levels of CPAP on composite indices of ventilation efficiency or respiratory muscle function in prematurely born infants. Yet, such a relationship would be plausible because adult studies demonstrate an unloading of the respiratory muscles with the application of $\mathrm{CPAP}^{9}$ and infants with bronchiolitis also manifest improved inspiratory muscle efficiency and respiratory muscle unloading when treated with CPAP. ${ }^{10}$ The aim of this study was to compare ventilation efficiency and respiratory muscle function at 3 different CPAP levels $\left(4,6\right.$, and $\left.8 \mathrm{~cm} \mathrm{H}_{2} \mathrm{O}\right)$ that are currently used in clinical practice.

\section{Methods}

\section{Subjects}

We retrospectively analyzed data collected during a study that assessed readiness for extubation. ${ }^{11}$ At King's College Hospital NHS Foundation Trust, infants born at $<34$ completed weeks of gestation without congenital anomalies and were on ventilation were eligible for study. The infants were ventilated with a Cole's endotracheal tube (size 2.5 or $3.0 \mathrm{~mm}$ ) on volume-targeted or pressure-controlled time-cycled ventilation with the SLE5000 neonatal ventilator or the SLE2000 infant ventilator (SLE, Croydon, United Kingdom). The study was approved by the London-Surrey Borders Research Ethics Committee. Written, informed parental consent was obtained. The study was

The authors have disclosed no conflicts of interest.

Correspondence: Theodore Dassios PhD, NICU, 4th Floor Golden Jubilee Wing, King's College Hospital, Denmark Hill, London, SE5 9RS. E-mail: theodore.dassios@kcl.ac.uk.

DOI: $10.4187 /$ respcare.06354

\section{QUICK LOOK}

\section{Current knowledge}

CPAP improves respiratory function by establishing and maintaining functional residual capacity and is widely used in neonatal intensive care. Adult and pediatric studies have demonstrated an unloading of the respiratory muscles with the application of CPAP.

\section{What this paper contributes to our knowledge}

Higher distending pressures on CPAP were associated with increased ventilation efficiency and enhanced respiratory muscle function. There was no further benefit above $6 \mathrm{~cm} \mathrm{H}_{2} \mathrm{O}$. The monitoring used could be incorporated into ventilator software and displayed in real time, thus aiding clinical decision making on optimal level of CPAP at the bedside.

registered with the Health Research Authority, NHS England (IRAS ID 193377).

\section{Study Protocol}

The infants were studied when they were clinically stable and ready for extubation. Extubation was considered, according to the unit policy, when $\mathrm{F}_{\mathrm{IO}_{2}}$ was $<0.4$, the infant had a pH of $>7.25, \mathrm{P}_{\mathrm{aCO}_{2}}$ of $<65 \mathrm{~mm} \mathrm{Hg}$, and the breathing frequency was higher than the set ventilator rate. ${ }^{12}$ All infants $<34$ weeks of postmenstrual age were receiving caffeine, ${ }^{13}$ and sedation was discontinued at least $12 \mathrm{~h}$ before measurement. When the clinical team decided that an infant was ready for extubation, the infant was switched from mechanical ventilation to endotracheal CPAP, and flow, volume, airway pressure, and expired $\mathrm{CO}_{2}$ were recorded. Each infant spent a total of $15 \mathrm{~min}$ on endotracheal CPAP, which consisted of 3 separate periods at CPAP levels of 4,6 , and $8 \mathrm{~cm} \mathrm{H}_{2} \mathrm{O}$ delivered in random order. During the spontaneous breathing on endotracheal CPAP, the oxygen saturation and heart rate were monitored. ${ }^{12}$

\section{Measuring Equipment}

The NM3 respiratory profile monitor (Philips Respironics, Wallingford, Connecticut) was used to measure flow, volume, airway pressure, and the concentration of expired $\mathrm{CO}_{2}$. The monitor was connected to a laptop (Dell Latitude, Dell, Bracknell, United Kingdom) with customized Spectra software 3.0.1.6, 2016 (Grove Medical, London, United Kingdom). The NM3 respiratory profile monitor had a combined $\mathrm{CO}_{2}$ and flow sensor that was placed between the endotracheal tube and the ventilator circuit. 


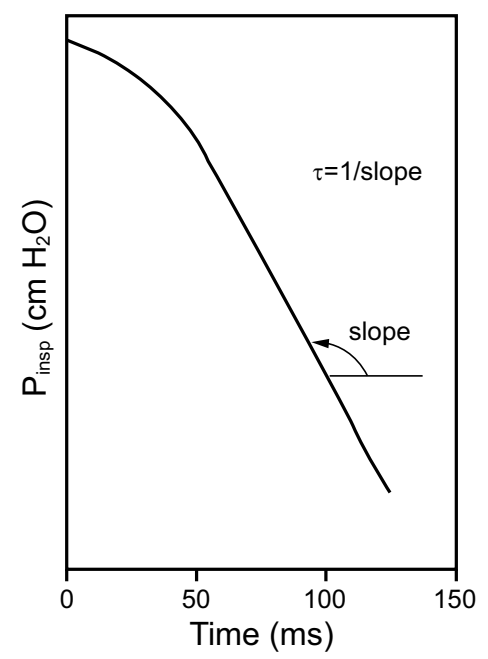

Fig. 1. Calculation of the time constant of relaxation of the respiratory muscles. $\mathrm{P}_{\text {insp }}=$ inspiratory pressure.

Expired $\mathrm{CO}_{2}$ was measured with a Capnostat-5 mainstream, infrared absorption spectroscopy $\mathrm{CO}_{2}$ sensor with a dead space of $<1 \mathrm{~mL}$ (Philips Respironics).

\section{Calculation of the Ventilation Efficiency Index and the Respiratory Muscle Time Constant or Relaxation}

The ventilation efficiency index was calculated from the formula:

$$
\text { Ventilation efficiency index }=3,800 / \Delta \mathrm{P} \times \mathrm{f} \times \mathrm{P}_{\mathrm{ETCO}_{2}}
$$

Where 3,800 is a constant for production of $\mathrm{CO}_{2}(\mathrm{~mL} / \mathrm{mm}$ $\mathrm{Hg} \mathrm{kg} / \mathrm{min}), \Delta \mathrm{P}$ is the difference between the spontaneously generated inspiratory pressure and the level of CPAP in $\mathrm{mm} \mathrm{Hg}$, $\mathrm{f}$ is the breathing frequency during spontaneous breathing, and $\mathrm{P}_{\mathrm{ETCO}_{2}}$ is the end-tidal carbon dioxide pressure in $\mathrm{mm} \mathrm{Hg} .{ }^{14}$ The respiratory muscle time constant of relaxation $(\tau)$ is an index of respiratory muscle fatigue ${ }^{15}$ and is calculated as the reciprocal of the absolute value of the slope of the pressure decline as a function of time at the lower $60 \%$ of the curve (Fig. 1). ${ }^{16}$ Higher values of $\tau$ signify a slower relaxation and impaired respiratory muscle function, whereas lower values of $\tau$ signify a faster relaxation and more efficient respiratory muscle function. ${ }^{15}$ The part of the airway pressure trace with smooth decay was hand selected and analyzed. Breaths with a waveform that exhibited evidence of expiratory diaphragmatic braking were excluded from the analysis. For each subject, the mean $\tau$ value of at least 5 consistent breaths was recorded. All assessments of airway pressure, $\mathrm{f}$, and $\mathrm{P}_{\mathrm{ETCO}_{2}}$ were undertaken at the last minute of the 5-min period spent at each level of CPAP. For the calculation of the ventilation efficiency index, the mean of all values of airway pres- sure and $\mathrm{P}_{\mathrm{ETCO}}$ during the last minute of the 5-min period were analyzed.

\section{Information From the Medical Records}

Sex, gestational age, birthweight, postmenstrual age, postnatal age, weight at the time of measurement, and total days of ventilation before the study were recorded. Birthweight $\mathrm{z}$ scores were calculated based on British national reference data. ${ }^{17}$ The $\mathrm{F}_{\mathrm{IO}_{2}}$ and the $\mathrm{P}_{\mathrm{aCO}_{2}}$ within $30 \mathrm{~min}$ before the measurement were also recorded from the nursing observation charts. Information recorded from the infant's medical notes included whether the infant had a patent ductus arteriosus, had been exposed to antenatal steroids, were given postnatal surfactant, or had had an intraventricular hemorrhage. A patent ductus arteriosus was diagnosed clinically and confirmed by echocardiography. Administration of antenatal corticosteroids was recorded as positive if at least 2 doses were given. The cranial ultrasound was recorded as normal if there was no intraventricular hemorrhage or intracranial pathology.

\section{Sample Size}

We retrospectively justified the size of our sample as sufficient to detect clinically important differences in the ventilation efficiency index. Pillow et al ${ }^{14}$ reported improved ventilation efficiency in an animal model of premature lambs at a mean (SD) difference in ventilation efficiency index of $0.10(0.08)$. Based on the above, 14 subjects would enable detection of a difference in ventilation efficiency index of 0.10 at different levels of CPAP, with $90 \%$ power at the $5 \%$ level.

\section{Statistics}

Data were tested for normality with the KolmogorovSmirnoff test and were found to be non-normally distributed. Hence, differences in tidal volume $\left(\mathrm{V}_{\mathrm{T}}\right), \mathrm{f}$, inspiratory pressure, $\mathrm{P}_{\mathrm{ETCO}_{2}}$, ventilation efficiency index, and $\tau$ at different CPAP levels were assessed for statistical significance by using the Kruskal-Wallis rank-sum test. The 2-tailed Mann-Whitney U test was used for pairwise post hoc comparisons between the individual groups. To assess the adjusted effect of the different levels of CPAP on the pulmonary function indices, the factors that were significantly different between the groups according to the level of CPAP $(P<.05)$ were inserted into a multiple logistic regression model with the level of CPAP as the outcome variable. Variables without normal distribution were logarithmically transformed. Multi-collinearity among the independent variables in the regression analysis was assessed by calculation of the tolerance for the inde- 


\section{Ventilation Efficiency and Respiratory Muscle Function in Premature Infants}

Table 1. Demographics and Ventilator Settings of the Included Infants

\begin{tabular}{|c|c|}
\hline Parameter & Result \\
\hline Gestational age, median (IQR) wk & $26.6(25.0-29.5)$ \\
\hline Birth weight, median (IQR) kg & $0.88(0.73-1.02)$ \\
\hline Birth weight z score, median (IQR) & $-0.56(-1.59$ to 0.10$)$ \\
\hline Boys, $n(\%)$ & $19(50)$ \\
\hline Age at study, median (IQR) d & $11(4-43)$ \\
\hline PMA at study, median (IQR) wk & $30.6(27.5-33.5)$ \\
\hline PDA, $n(\%)$ & $8(21)$ \\
\hline Antenatal steroids, $n(\%)$ & $31(82)$ \\
\hline Postnatal surfactant, $n(\%)$ & $38(100)$ \\
\hline Caffeine at study, $n(\%)$ & $38(100)$ \\
\hline IVH grade II, III, or IV, $n(\%)$ & $9(24)$ \\
\hline $\mathrm{F}_{\mathrm{IO}_{2}}$, median $(\mathrm{IQR})$ & $0.27(0.22-0.36)$ \\
\hline $\begin{array}{l}\text { Mean airway pressure, median } \\
\text { (IQR) } \mathrm{cm} \mathrm{H}_{2} \mathrm{O}\end{array}$ & $8(7-9)$ \\
\hline $\mathrm{P}_{\mathrm{aCO}_{2}}$, median (IQR) mm Hg & $47.7(41.2-53.0)$ \\
\hline $\mathrm{pH}$, median (IQR) & $7.36(7.32-7.41)$ \\
\hline $\begin{array}{l}\text { Ventilation days before the } \\
\text { study, median (IQR) }\end{array}$ & $8(3-35)$ \\
\hline $\begin{array}{l}N=38 . \\
\text { IQR = interquartile range } \\
\text { PMA = postmenstrual age } \\
\text { PDA = patent ductus arteriosus } \\
\text { IVH = intraventricular hemorrhage }\end{array}$ & \\
\hline
\end{tabular}

pendent variables. Statistical analysis was performed by using SPSS software (SPSS, Chicago, Illinois).

\section{Results}

Between February 1, 2016, and August 1, 2016, 38 infants (19 boys) with a median gestational age of 26.6 (IQR, 25.0-29.5) wk and a median birthweight of 0.88 (IQR, 0.73-1.02) $\mathrm{kg}$ were included in the study (Table 1). All the infants were given surfactant after birth. The infants were studied at a median postmenstrual age of 30.6 (IQR, 27.5-33.5) wk and at the time of the study had a median $\mathrm{F}_{\mathrm{IO}_{2}}$ requirement of 0.27 (IQR, 0.22-0.36), and median $\mathrm{P}_{\mathrm{aCO}}$ of 47.7 (IQR, 41.2-53.0) mm Hg (Table 1). The $\mathrm{V}_{\mathrm{T}} / \mathrm{kg}$ of body weight and the $\mathrm{P}_{\mathrm{ETCO}_{2}}$ levels were not significantly different at CPAP levels of 4,6 , or $8 \mathrm{~cm} \mathrm{H}_{2} \mathrm{O}$ (Table 2).

\section{CPAP of 4 Versus $6 \mathrm{~cm} \mathrm{H}_{2} \mathrm{O}$}

At a CPAP level of $6 \mathrm{cmH}_{2} \mathrm{O}$, the median inspiratory pressure and ventilation efficiency index were significantly higher compared with the inspiratory pressure and ventilation efficiency index, at a CPAP level of $4 \mathrm{~cm} \mathrm{H}_{2} \mathrm{O}$ $(P<.001$ for both) (Table 2, Fig. 2). At a CPAP level of $6 \mathrm{~cm} \mathrm{H}_{2} \mathrm{O}$, the median $\tau$ was lower compared with the $\tau$ at a CPAP level of $4 \mathrm{~cm} \mathrm{H}_{2} \mathrm{O}(P=.005)$ (Table 2).

\section{CPAP of 6 Versus $8 \mathrm{~cm} \mathrm{H}_{2} \mathrm{O}$}

At a CPAP level of $8 \mathrm{~cm} \mathrm{H}_{2} \mathrm{O}$, the median inspiratory pressure was higher compared with the inspiratory pressure at a CPAP level of $6 \mathrm{~cm} \mathrm{H}_{2} \mathrm{O}$. At a CPAP level of $8 \mathrm{~cm} \mathrm{H}_{2} \mathrm{O}$, the median ventilation efficiency index was lower compared with the ventilation efficiency index at a CPAP level of $6 \mathrm{~cm} \mathrm{H}_{2} \mathrm{O}(P<.001)$ (Table 2, Fig. 2). At a CPAP level of $8 \mathrm{~cm} \mathrm{H}_{2} \mathrm{O}$, the median $\tau$ was not significantly lower compared with the $\tau$ at a CPAP level of $6 \mathrm{~cm} \mathrm{H}_{2} \mathrm{O}(P=.12)$ (Table 2). Multivariate regression analysis demonstrated that the level of CPAP was independently associated with inspiratory pressure (adjusted $P<.001$ ), ventilation efficiency index (adjusted $P<.001$ ), and $\tau$ (adjusted $P=.003$ ) but not with $\mathrm{f}$ (Table 3 ).

\section{Discussion}

We demonstrated that increasing the distending pressure on CPAP from 4 to $6 \mathrm{~cm} \mathrm{H}_{2} \mathrm{O}$ was associated with an improvement in ventilation efficiency and respiratory muscle function, but a further increase to $8 \mathrm{~cm} \mathrm{H}_{2} \mathrm{O}$ was associated with decreased ventilation efficiency and no further improvement in respiratory muscle function. Previous studies report how increasing the level of CPAP affects respiratory function. ${ }^{6-8,18}$ Elgellab et $\mathrm{al}^{7}$ used respiratory inductive plethysmography to measure lung volumes in 10 premature infants on nasal CPAP at a pressure of $0,2,4,6$, and $8 \mathrm{~cm} \mathrm{H}_{2} \mathrm{O}$, and reported that increased pressure was associated with a higher end-expiratory lung volume, higher $\mathrm{V}_{\mathrm{T}}$, and less thoraco-abdominal asynchrony. More recently, Miedema et $\mathrm{al}^{6}$ used electrical impedance tomography in 22 premature infants at a pressure of 2, 4, and $6 \mathrm{~cm} \mathrm{H}_{2} \mathrm{O}$, and similarly reported an increase in end-expiratory lung volume and $\mathrm{V}_{\mathrm{T}}$, and a decrease in thoracoabdominal asynchrony with increased CPAP. Pickerd et $\mathrm{al}^{8}$ used electromagnetic inductive plethysmography at 5,7 , and $9 \mathrm{~cm} \mathrm{H}_{2} \mathrm{O}$, and reported higher $\mathrm{V}_{\mathrm{T}}$ with higher CPAP levels.

Furthermore, Bhatia et al ${ }^{18}$ studied 20 premature infants with electrical impedance tomography and demonstrated that manipulation of the distending pressure can be used as a maneuver to optimize lung volume in the preterm lung. Our study complemented the literature by studying a larger cohort, which consisted of extremely premature infants at a critical time before extubation when the level of postextubation support would be decided. Furthermore, our study reported that the beneficial effects of CPAP on ventilation efficiency and respiratory muscle function did not persist beyond the level of $6 \mathrm{~cm} \mathrm{H}_{2} \mathrm{O}$, because, at a level of $8 \mathrm{~cm} \mathrm{H} \mathrm{H}_{2} \mathrm{O}$, ventilation efficiency was significantly re- 
Table 2. Pulmonary Function Assessments According to Level of CPAP

\begin{tabular}{|c|c|c|c|c|}
\hline Variable & $4 \mathrm{~cm} \mathrm{H}_{2} \mathrm{O}$ & $6 \mathrm{~cm} \mathrm{H}_{2} \mathrm{O}$ & $8 \mathrm{~cm} \mathrm{H}_{2} \mathrm{O}$ & $P$ \\
\hline $\mathrm{V}_{\mathrm{T}}, \mathrm{mL}$ & $7.2(5.3-9.7)$ & $7.3(5.7-9.0)$ & $7.8(6.3-9.6)$ & .78 \\
\hline $\mathrm{V}_{\mathrm{T}}, \mathrm{mL} / \mathrm{kg}$ & $5.7(4.6-6.8)$ & $6.1(5.3-7.4)$ & $6.6(5.8-7.6)$ & .10 \\
\hline f & $73(63-84)$ & $67(59-76)$ & $60(50-73)$ & $.007 *$ \\
\hline Spontaneously generated inspiratory pressure, $\mathrm{cm} \mathrm{H}_{2} \mathrm{O}$ & $5.7(5.4-6.7)$ & $7.1(6.4-7.6)$ & $9.2(8.8-9.8)$ & $<.001 \dagger$ \\
\hline $\mathrm{P}_{\mathrm{ETCO}_{2}}, \mathrm{~mm} \mathrm{Hg}$ & $45.3(36.1-52.0)$ & $41.9(35.1-47.3)$ & $40.4(35.3-45.6)$ & .48 \\
\hline Ventilation efficiency index & $0.75(0.56-1.03)$ & $1.52(1.02-2.27)$ & $1.27(1.04-1.91)$ & $<.001 \dagger$ \\
\hline$\tau, \mathrm{s} / \mathrm{cm} \mathrm{H}_{2} \mathrm{O}$ & $23.3(15.4-35.2)$ & $15.6(10.1-21.3)$ & $11.2(8.3-18.9)$ & $.001 \S$ \\
\hline \multicolumn{5}{|c|}{ 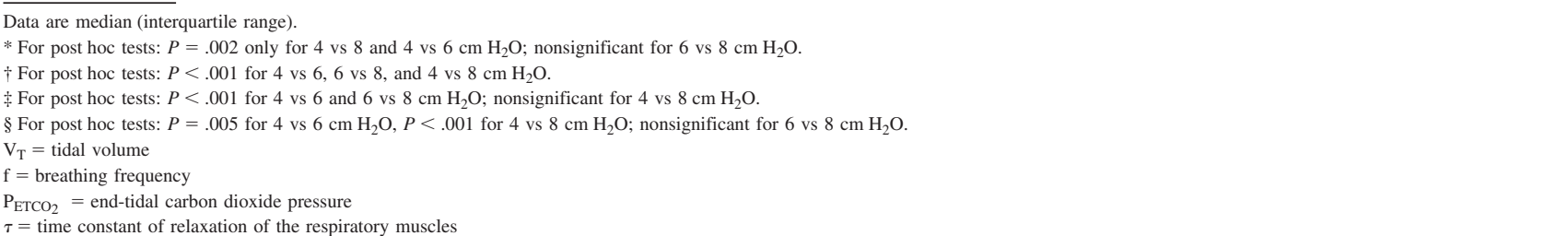 } \\
\hline
\end{tabular}

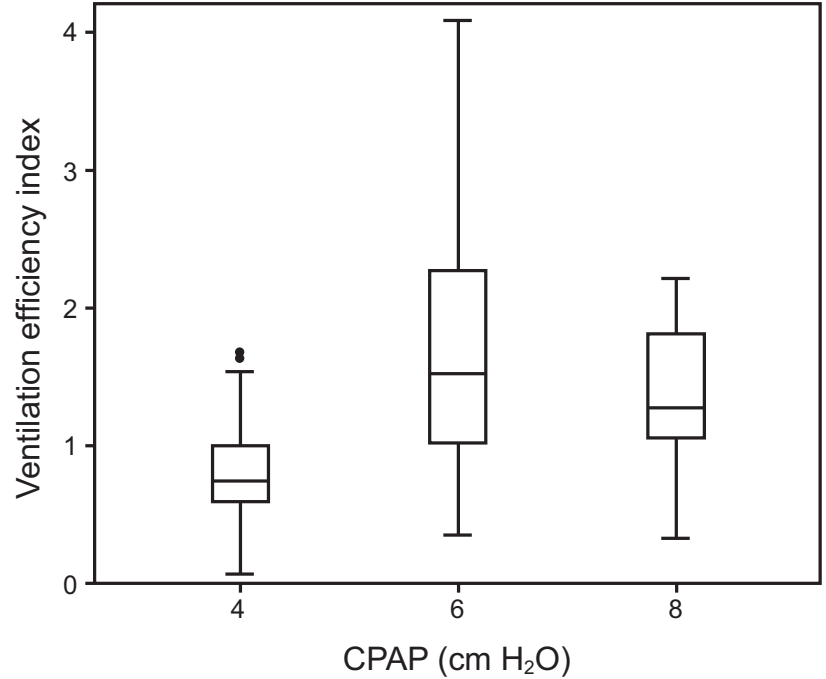

Fig. 2. Ventilation efficiency index at CPAP levels of 4, 6, and $8 \mathrm{~cm} \mathrm{H} \mathrm{H}_{2} \mathrm{O}$. Boxes represent 25th, 50th, and 75th percentiles; whiskers show 5th and 95th percentiles; points are outliers.

duced and respiratory muscle function was not significantly better. This was in agreement with Greenough et al ${ }^{19}$ who demonstrated that, in infants on mechanical ventilation studied at a median postnatal age of $15 \mathrm{~d}$, a PEEP of $6 \mathrm{~cm} \mathrm{H}_{2} \mathrm{O}$ was associated with improved oxygenation compared with a pressure of $3 \mathrm{~cm} \mathrm{H}_{2} \mathrm{O}$.

Contrary to the aforementioned studies, the $\mathrm{V}_{\mathrm{T}}$ in our study was not significantly higher at increasing levels of CPAP. Those differences might be explained by population and methodologic differences: Our infants were well enough to be considered for extubation and were studied while intubated. Intubation might have impacted on the mechanics of the respiratory system by bypassing the contribution of the upper airways and by imposing an added resistance, which corresponds to the endotracheal tube. ${ }^{20}$

We elected to use the ventilation efficiency index in our study because it is a composite index of ventilation that incorporates information on both the input (breathing frequency and pressures) and the output $\left(\mathrm{CO}_{2}\right)$ of the process of ventilation being an ideal index to describe ventilation efficiency. In our study, we reported values of ventilation efficiency index that were relatively higher than in previously published studies ${ }^{14,21}$; this was due to the relatively lower spontaneously generated inspiratory pressure in our study, which might be explained by the dampening of the pressure in the endotracheal tube. Furthermore, to avoid excessive arterial blood sampling over a very short period of time, we used $\mathrm{P}_{\mathrm{ETCO}_{2}}$ and not arterial $\mathrm{CO}_{2}$ values. When compared with term-born infants, premature infants have an increased anatomic dead space, so $\mathrm{P}_{\mathrm{ETCO}_{2}}$ is very likely to be lower than arterial $\mathrm{CO}_{2} .{ }^{22} \mathrm{We}$ studied the range of CPAP levels in each infant, so factors like the increased dead space and relatively increased ventilation efficiency index did not influence the validity of our conclusions.

We also elected to use the respiratory muscle time constant of relaxation to assess respiratory muscle function. The airway pressure decay is a proxy for the rate of relaxation of the respiratory muscles and a well-described measure of respiratory muscle fatigue. ${ }^{15} \tau$ has been used to successfully predict the outcome of extubation in studies of adults on ventilation. ${ }^{23}$ We previously used the same methodology to demonstrate that $\tau$ can successfully predict the outcome of extubation in prematurely born infants ${ }^{11}$ and that respiratory muscle function in newborns is negatively and independently associated with the degree of immaturity and the presence of systemic or respiratory infection. ${ }^{24}$ Invasive or more complex methods, such as the estimation of the diaphragmatic tension-time index ${ }^{25}$ 
Table 3. Multiple Regression Analysis of Pulmonary Function Indices With the Level of CPAP as the Outcome Variable

\begin{tabular}{lccc}
\hline \hline \multicolumn{1}{c}{ Variable } & Odds Ratio & $95 \%$ CI & $P$ \\
\hline $\mathrm{f}$ & -0.007 & -0.006 to 0.005 & .90 \\
Spontaneously generated inspiratory pressure & 0.823 & $0.329-0.436$ & $<.001$ \\
Ventilation efficiency index & 0.417 & $0.211-0.377$ & -0.014 to -0.003 \\
$\tau$ & -0.172 & & .003 \\
& & & \\
$\mathrm{f}=$ breathing frequency & & & \\
$\tau=$ time constant of relaxation of the respiratory muscles & & & \\
\hline
\end{tabular}

or diaphragmatic electromyography, ${ }^{26}$ would focus on diaphragmatic function rather than on all respiratory muscles. The advantage of our approach was that qualitative analysis of the pressure waveform and the corresponding time constant of respiratory muscle relaxation can be incorporated into ventilator software and displayed in real time, which thus aids clinical decision-making on the optimal level of CPAP at the bedside.

The findings of our study are physiologically plausible. The sigmoid nature of the compliance curve of the respiratory system would dictate that the work of breathing was increased in both ends of the pressure spectrum. Achieving a set $\mathrm{V}_{\mathrm{T}}$ at relatively low pressures is energy inefficient because of atelectasis and lung de-recruitment at low pressures. Similarly, at relatively high pressures, the work of breathing would also increase because of the effect of hyperinflation on diaphragmatic contractility, which thus left an optimal ventilation zone in-between these 2 extremes. ${ }^{27}$ Our study highlighted that the majority of convalescent prematurely born infants would be in this zone at a distending pressure of $6 \mathrm{~cm} \mathrm{H}_{2} \mathrm{O}$.

Recent animal studies in ARDS furthered our understanding of how a higher level of CPAP could be beneficial to respiratory function. A higher PEEP minimized dependent lung injury via lung stress and stretch in adults with severe ARDS and animal models of ARDS, ${ }^{28}$ whereas a PEEP of $5 \mathrm{~cm} \mathrm{H}_{2} \mathrm{O}$ but not a PEEP of $2 \mathrm{~cm} \mathrm{H}_{2} \mathrm{O}$ reduced lung damage and inflammatory markers. ${ }^{29}$

Our study had strengths and some limitations. To our knowledge, this was the first study to describe respiratory muscle function changes at different levels of CPAP in premature infants on ventilation. This study was conducted in infants on ventilation and had the obvious methodologic advantage of accurate pressure and $\mathrm{CO}_{2}$ measurements. Previous plethysmographic studies could not have measured and analyzed the pressure waveform that provides the surrogate for the assessment of the respiratory muscles. Furthermore, measurement of $\mathrm{CO}_{2}$, and thus ventilation efficiency, cannot be undertaken in infants who were not on ventilation without the application of a face mask, which, by adding a significant dead space, might considerably impact the accuracy of the measurements and even on the breathing pattern. ${ }^{30}$ In our study, we included a population that was studied at varying ages and $\mathrm{F}_{\mathrm{IO}_{2}}$ requirements. A more homogeneous population might have decreased the variation in our outcome measures, but we believe that our population mirrored the corresponding variation encountered in everyday clinical practice.

We acknowledge as a limitation that this study was conducted on stable infants on ventilation and our results might not be directly translatable to the level of CPAP that is required when given in a noninvasive manner or in prematurely born infants studied during the acute phase of respiratory distress syndrome. Because this was a crossover study of the same infants, however, the relationship of unloading the respiratory muscles and increasing the ventilation efficiency with increasing levels of CPAP was valid. Previous studies question the validity of tidal capnographic measurements in premature infants due to technical limitations that arise from the high proportion of instrumental dead space to $V_{T}$ and the breathing pattern of premature infants, which involves high rates and, commonly, the absence of an alveolar plateau phase. ${ }^{31}$ In our study, however, we used a capnograph with the lowest available dead space, so this error has been minimized. Also, because the same methodology was used to measure $\mathrm{P}_{\mathrm{ETCO}_{2}}$, the relative change in $\mathrm{P}_{\mathrm{ETCO}_{2}}$ at different levels of $\mathrm{CPAP}$ would also be valid.

\section{Conclusions}

We demonstrated that increasing the distending pressures of CPAP from 4 to $6 \mathrm{~cm} \mathrm{H}_{2} \mathrm{O}$ was associated with enhanced ventilation efficiency and respiratory muscle function, but there was no further benefit from exceeding a level of $6 \mathrm{~cm} \mathrm{H}_{2} \mathrm{O}$.

\section{ACKNOWLEDGMENTS}

We thank the Statistical Consultancy Service, Division of Health and Social Care Research, King's College London for statistical assistance.

\section{REFERENCES}

1. Morley CJ, Davis PG, Doyle LW, Brion LP, Hascoet JM, Carlin JB; COIN Trial Investigators. Nasal CPAP or intubation at birth for very preterm infants. N Engl J Med 2008;358(7):700-708. 


\section{Ventilation Efficiency and Respiratory Muscle Function in Premature Infants}

2. Morley C. Continuous positive airway pressure. In: Donn SM, Sinha SK, editors. Manual of Neonatal Respiratory Care. New York: Springer-Verlag; 2012.

3. Gupta S, Donn SM. Continuous positive airway pressure: physiology and comparison of devices. Semin Fetal Neonatal Med 2016;21(3): 204-211.

4. Decramer M. Hyperinflation and respiratory muscle interaction. Eur Respir J 1997;10(4):934-941.

5. Keszler M, Abubakar MK. Physiologic principles. In: Goldsmith JP, Karotkin E, Keszler M, Suresh G, editors. Assisted ventilation of the neonate: evidence-based approach to newborn respiratory care. Philadelphia: Elsevier; 2016.

6. Miedema M, van der Burg PS, Beuger S, de Jongh FH, Frerichs I, van Kaam AH. Effect of nasal continuous and biphasic positive airway pressure on lung volume in preterm infants. J Pediatr 2013; 162(4):691-697.

7. Elgellab A, Riou Y, Abbazine A, Truffert P, Matran R, Lequien P, Storme L. Effects of nasal continuous positive airway pressure (NCPAP) on breathing pattern in spontaneously breathing premature newborn infants. Intensive Care Med 2001;27(11):1782-1787.

8. Pickerd N, Williams EM, Watkins WJ, Kotecha S. Tidal breathing in preterm infants receiving and weaning from continuous positive airway pressure. J Pediatr 2014;164(5):1058-1063.e1.

9. Chadda K, Annane D, Hart N, Gajdos P, Raphaël JC, Lofaso F. Cardiac and respiratory effects of continuous positive airway pressure and noninvasive ventilation in acute cardiac pulmonary edema. Crit Care Med 2002;30(11):2457-2461.

10. Cambonie G, Milési C, Jaber S, Amsallem F, Barbotte E, Picaud JC, Matecki S. Nasal continuous positive airway pressure decreases respiratory muscles overload in young infants with severe acute viral bronchiolitis. Intensive Care Med 2008;34(10):1865-1872.

11. Dassios T, Kaltsogianni O, Greenough A. Relaxation rate of the respiratory muscles and prediction of extubation outcome in prematurely born infants. Neonatology 2017;112(3):251-257.

12. Kamlin CO, Davis PG, Morley CJ. Predicting successful extubation of very low birthweight infants. Arch Dis Child Fetal Neonatal Ed 2006;91(3):F180-F183.

13. Schmidt B, Roberts RS, Davis P, Doyle LW, Barrington KJ, Ohlsson A, et al; Caffeine for Apnea of Prematurity Trial Group. Caffeine therapy for apnea of prematurity. N Engl J Med 2006;354(20):2112-2121.

14. Pillow JJ, Musk GC, McLean CM, Polglase GR, Dalton RG, Jobe $\mathrm{AH}$, Suki B. Variable ventilation improves ventilation and lung compliance in preterm lambs. Intensive Care Med 2011;37(8):1352-1359.

15. American Thoracic Society/European Respiratory Society. ATS/ERS Statement on respiratory muscle testing. Am J Respir Crit Care Med 2002;166(4):518-624.

16. Dassios T, Kaditis A, Katelari A, Chrousos G, Doudounakis S, Dimitriou G. Time constant of inspiratory muscle relaxation in cystic fibrosis. Pediatr Res 2015;77(4):541-545.
17. Wright CM, Booth IW, Buckler JM, Cameron N, Cole TJ, Healy MJ, et al. Growth reference charts for use in the United Kingdom. Arch Dis Child 2002;86(1):11-14.

18. Bhatia R, Davis PG, Tingay DG. Regional volume characteristics of the preterm infant receiving first intention continuous positive airway pressure. J Pediatr 2017;187:80-88.e2.

19. Greenough A, Chan V, Hird MF. Positive end expiratory pressure in acute and chronic respiratory distress. Arch Dis Child 1992;67(3): 320-323.

20. Manczur T, Greenough A, Nicholson GP, Rafferty GF. Resistance of pediatric and neonatal endotracheal tubes: influence of flow rate, size, and shape. Crit Care Med 2000;28(5):1595-1598.

21. Jobe AH, Moss TJ, Nitsos I, Ikegami M, Kallapur SG, Newnham JP. Betamethasone for lung maturation: testing dose and formulation in fetal sheep. Am J Obstet Gynecol 2007;197(5):523.e1-6.

22. Dassios T, Dixon P, Hickey A, Fouzas S, Greenough A. Physiological and anatomical dead space in mechanically ventilated newborn infants. Pediatr Pulmonol 2018;53(1):57-63.

23. Goldstone JC, Green M, Moxham J. Maximum relaxation rate of the diaphragm during weaning from mechanical ventilation. Thorax 1994; 49(1):54-60.

24. Dassios T, Kaltsogianni O, Dixon P, Greenough A. Effect of maturity and infection on the rate of relaxation of the respiratory muscles in ventilated, newborn infants. Acta Paediatr 2018;107(4):587-592.

25. Gaultier C. Tension-time index of inspiratory muscles in children. Pediatr Pulmonol 1997;23(5):327-329.

26. Kassim Z, Jolley C, Moxham J, Greenough A, Rafferty GF. Diaphragm electromyogram in infants with abdominal wall defects and congenital diaphragmatic hernia. Eur Respir J 2011;37(1):143-149.

27. Harris RS, Hess DR, Venegas JG. An objective analysis of the pressure-volume curve in the acute respiratory distress syndrome. Am J Respir Crit Care Med 2000;161(2 pt 1):432-439.

28. Morais CCA, Koyama Y, Yoshida T, Plens GM, Gomes S, Lima $\mathrm{CAS}$, et al. high positive end-expiratory pressure renders spontaneous effort noninjurious. Am J Respir Crit Care Med 2018;197(10): 1285-1296.

29. Magalhães PAF, Padilha GA, Moraes L, Santos CL, Maia LA, Braga $\mathrm{CL}$, et al. Effects of pressure support ventilation on ventilator-induced lung injury in mild acute respiratory distress syndrome depend on level of positive end-expiratory pressure: A randomised animal study. Eur J Anaesthesiol 2018;35(4):298-306.

30. Hishikawa K, Fujinaga H, Ito Y. Increased dead space in face mask continuous positive airway pressure in neonates. Pediatr Pulmonol 2017;52(1):107-111.

31. Schmalisch G. Current methodological and technical limitations of time and volumetric capnography in newborns. Biomed Eng Online 2016;15(1):104. 